\title{
Building A Predictive Model of Indoor Concentrations of Outdoor PM-2.5 in Homes
}

\author{
Melissa M. Lunden, Tracy L. Thatcher, David Littlejohn, Marc L. Fischer, \\ Thomas W. Kirchstetter, and Nancy J. Brown \\ Environmental Energy Technologies Division \\ Lawrence Berkeley National Laboratory \\ Berkeley, CA 94720-1740 \\ and
}

Susanne Hering and Mark Stolzenburg

Aerosol Dynamics Inc.

2329 Fourth St.

Berkeley, CA 94710

SEPTEMBER, 2001

\author{
Contact person \\ Dr. Nancy J. Brown \\ Phone: (510) 486-4241 \\ Fax: (510) 486-7303 \\ e-mail: nibrown@lbl.gov
}

This research was supported by the Assistant Secretary for Fossil Energy, Office of Natural Gas and Petroleum Technology, through the National Petroleum Technology Office under U.S. Department of Energy Contract No. DE-AC03-76SF00098. 


\section{ABSTRACT}

The goal of this project is to develop a physically-based, semi-empirical model that describes the concentration of indoor concentration of PM-2.5 (particle mass that is less than 2.5 microns in diameter) and its sulfate, nitrate, organic and black carbon constituents, derived from outdoor sources. We have established the methodology and experimental plan for building the model. Experimental measurements in residential style houses, in Richmond and Fresno, California, are being conducted to provide parameters for and evaluation of this model. The model will be used to improve estimates of human exposures to PM-2.5 of outdoor origin. The objectives of this study are to perform measurement and modeling tasks that produce a tested, semi-mechanistic description of chemical species-specific and residential PM-2.5 arising from the combination of outdoor $\mathrm{PM}$ and gas phase sources $\left(\mathrm{HNO}_{3}\right.$ and $\left.\mathrm{NH}_{3}\right)$, and indoor gas phase (e.g. $\left.\mathrm{NH}_{3}\right)$ sources. We specifically address how indoor PM is affected by differences between indoor and outdoor temperature and relative humidity. In addition, we are interested in losses of particles within the building and as they migrate through the building shell. The resulting model will be general enough to predict probability distributions for species-specific indoor concentrations of PM-2.5 based on outdoor PM, and gas phase species concentrations, meteorological conditions, building construction characteristics, and HVAC operating conditions.

Controlled intensive experiments were conducted at a suburban research house located in Clovis, California. The experiments utilized a large suite of instruments including conventional aerosol, meteorological and house characterization devices. In addition, two new instruments were developed providing high time resolution for the important particulate species of nitrate, sulfate, and carbon as well as important gaseous species including ammonia and nitric acid. Important initial observations include the result that, with rare exceptions, there is virtually no nitrate found inside the house. This nitrate appears to dissociate into ammonia and nitric acid with the nitric acid quickly depositing out. Initial model development has included work on characterizing penetration and deposition rates, the dynamic behavior of the indoor/outdoor ratio, and predicting infiltration rates. Results from the exploration of the indoor/outdoor ratio show that the traditional assumption of steady state conditions does not hold in general. Many values of the indoor/outdoor ratio exist for any single value of the infiltration rate. Successful prediction of the infiltration rate from measured driving variables is important for extending the results from the Clovis house to the larger housing stock. 


\section{INTRODUCTION}

A major scientific issue is understanding the underlying reasons for the causes of adverse health effects resulting from ambient particulate matter (PM). Key to beginning to understand this issue is determining the actual exposure of the population to outdoor PM-2.5 (particle matter less than 2.5 microns in diameter). Investigation of quantitative relationships between particulatematter concentrations measured at stationary outdoor monitoring sites and the actual breathingzone exposures of individuals to particulate matter has been identified by the National Research Council Committee on Research Priorities for Airborne Particulate Matter (1998) as one of the ten top research priorities. Determining indoor concentration is particularly crucial because individuals spend, on average, about $90 \%$ of the time indoors ( $70 \%$ in homes) (Jenkins, et al., 1992). If indoor concentrations of outdoor PM-2.5 cannot be quantified, then personal exposures cannot be estimated based on outdoor monitoring sites. If exposures are not adequately characterized, then causal relationships between outdoor PM-2.5 and health effects may be erroneously attributed.

Prior studies of indoor and outdoor particle concentrations have taken two forms: mechanistic and phenomenological. Mechanistic studies evaluate the relationship between indoor and outdoor concentrations based on detailed measurements made under controlled conditions, in a laboratory setting or in a single room or house. These studies have provided valuable insights into mechanisms, but rely on very detailed and generally unavailable data as inputs. Phenomenological studies typically measure indoor to outdoor concentration ratios in a single house or a small sample of houses but without the ancillary physics-related measurements that are needed to provide predictive capability.

This study aims to develop a physically-based semiempirical model that predicts the concentration of outdoor PM-2.5 in the indoor environment using outdoor monitoring data and other readily available data as inputs. This type of model is commonly used in environmental engineering. The term "semi-empirical" implies that the mathematical form of the governing equations is consistent with the dominant physical and chemical processes, and that the model includes one or more parameters that are determined from experiment. The parameters may also be distributions that are sampled, using Monte Carlo methods, to provide estimates of the distributions of the dependent variable, e.g., concentrations of outdoor PM-2.5 for houses in a region. This modeling approach is more powerful than purely empirical descriptions in that significant extrapolation beyond the boundaries of the circumstances tested is possible.

Development of such a model to estimate concentrations of outdoor PM-2.5 from outdoor measurements is feasible because there is now a substantial body of experimental data and modeling research which indicates that the major physical factors controlling indoor concentrations of outdoor PM-2.5 in residential buildings are: ventilation rate, deposition losses to indoor and building envelope surfaces, and phase changes that result from transport to the indoor environment.

Under Task 1 of our project we the outlined a semi-empirical model for estimating indoor concentrations of outdoor PM, and we enumerated the parameters that must be determined through experimental measurements. A well-controlled set of experiments was designed to 
provide the input needed to refine and parameterize this model. Where necessary, our Task 1 efforts included development of new, real-time measurement methods.

This report presents our efforts under Task 2, Controlled Experiments in a Research House, and Task 3, Model Refinement and Parameterization. Our research house is located in Clovis, California, a suburb of Fresno, in California's San Joaquin Valley. Measurements were made during the late summer 2000, and during the winter, 2000-2001, coincident with the California Regional Particulate Air Quality Study (CRAPQS). The measurements focused on providing data on indoor and outdoor concentration relationships for sub-2.5 um particles (PM-2.5) as a function of size and chemical composition under a variety of configurations for the house ventilation, heating and cooling. Indoor sources were minimized to allow the quantitation of indoor concentrations of particles of outdoor origin. This report presents the initial data from these experiments, and the modeling results derived from then.

\section{TASK 2: CONTROLLED EXPERIMENTS IN RESEARCH HOUSE: EXPERIMENTAL METHODS}

\section{Study Location and Equipment}

The experimental research facility is a moderate sized home $\left(134 \mathrm{~m}^{2}\right)$ located in Clovis, CA and constructed in 1972. It has a stucco exterior and sliding, aluminum frame windows. The house is single story, with standard height ceilings $(2.4 \mathrm{~m})$, a forced air heating and cooling system, and ceiling fans, which were operated during the experiments to promote mixing. The structure has a relatively low air exchange rate, with a normalized leakage area, as measured with a blower door, of 0.65 . The house is located in a residential suburb, surrounded by mature trees and homes of a similar height and size. The flat terrain and high level of sheltering resulted in relatively low levels of wind loading near the building. Figure 1 shows a floor plan of the home.

The indoor particle and gas measurement devices were all located in the living room. Systems to measure tracer gas concentration and pressure differentials across the building shell monitored the living room location as well as several locations throughout the house, as shown in Figure 1. The following suite of instruments were installed at the experimental facility to measure the quantities listed:

1) Optical particle counters (size distribution for particles with diameters 0.1 to $3 \mu \mathrm{m}$ )

2) Aerodynamic particle counters (size distribution for particles with diameters 0.5 to 10 $\mu \mathrm{m})$

3) Condensation nucleus counters (total particle counts)

4) Integrated collection and vaporization system (ten-minute integrated samples of PM2.5 nitrate, carbon, and sulfate)

5) Ion chromatograph system (15 minute integrated samples of ions from soluble atmospheric gases: ammonia, nitrite, nitrate, and sulfate)

6) Aetholometer (20 minute integrated measurements of PM-2.5 black carbon)

7) Nephelometer (light scattering coefficient of suspended aerosol)

8) Filter sampling manifold (12 hour integrated PM-2.5 carbon, nitrate, ammonium, and total mass)

9) Meteorological system (wind speed, direction, temperature, relative humidity) 
10) Tracer gas injection and detection system (air exchange rate based on tracer gas concentrations at a constant injection rate)

11) Automated pressure testing system (pressure differential across the building shell and vertical temperature profile indoors).

Many of these systems are commercially available and commonly used in air quality studies.

For the systems, which were custom made for this study, the following sections contain complete descriptions of the instruments.

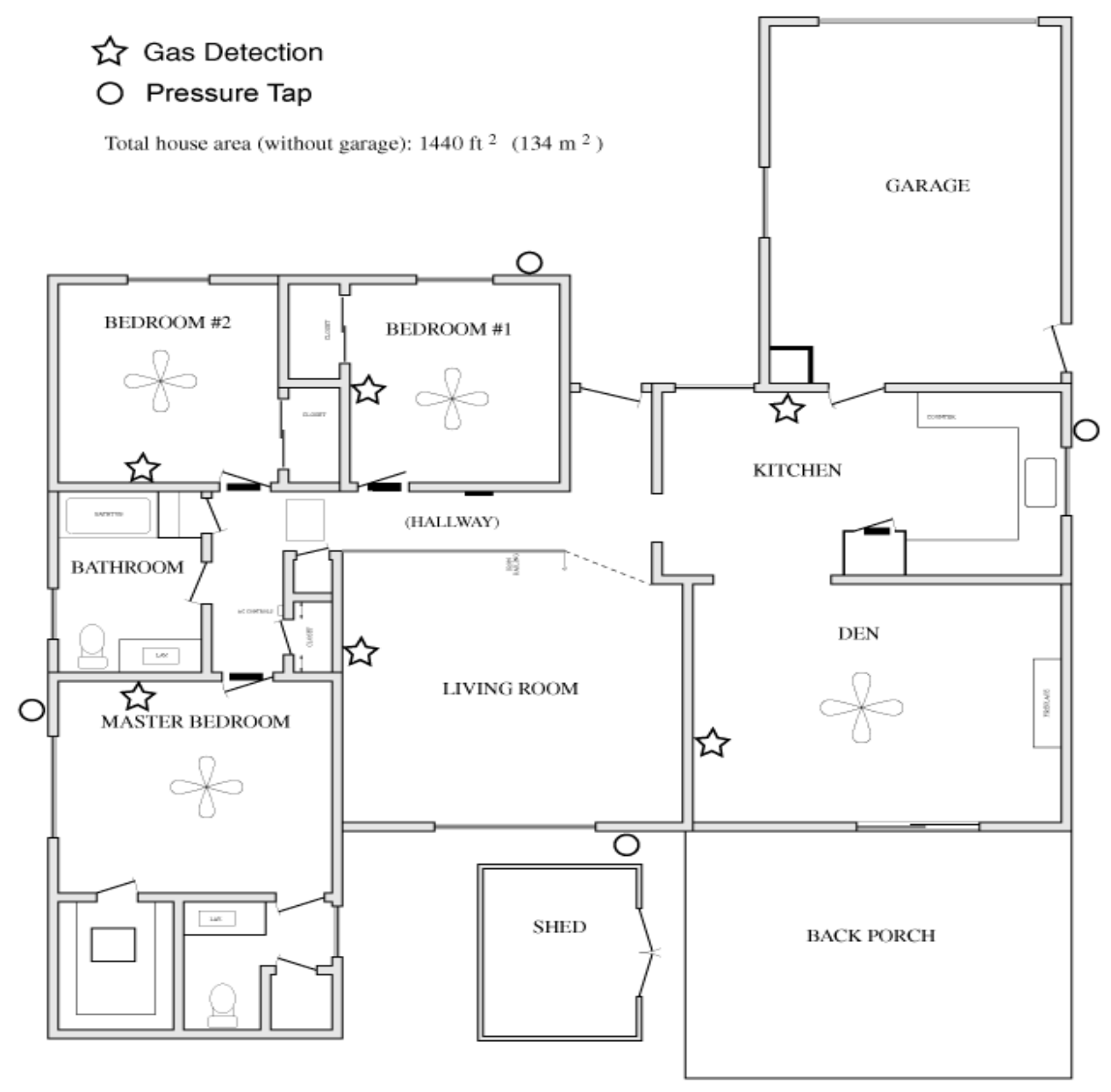

Figure 1. The floor plan of the Clovis research house. The stars denote gas sampling locations for the tracer gas system and the circles denote locations of pressure taps to measure the pressure difference across the building shell. 


\section{Measurement Protocol}

Experimental measurements were conducted in two phases, from August through October 2000, and again from December 2000 through January 2001. Within these measurement periods, several weeks were used for intensive measurements which included 12-hour filter- based measurements of particle chemistry, tracer gas release for ventilation rate determination, and manual manipulation of the house configuration, as described below. Intensive measurements were made from October 9-23, December 11 to 19, 2000 and January 16 to 23, 2001.

In October most measurements were made with the house closed, and with ventilation controlled by natural driving conditions, that is wind and temperature. The data in October showed that the house displayed a relatively limited range of infiltration rates when allowed to operate under naturally occurring driving conditions. These values ranged in value from 0.2 to 0.5 air changes per hour $(\mathrm{ACH})$, only becoming significantly higher when all of the doors and windows of the house were opened. At these lower infiltration rates we observed a large degree of dissociation of the nitrate aerosol to nitric acid and ammonia, resulting in a very small amount of nitrate aerosol inside the house.

While it is important to characterize this natural behavior, we wanted to further explore the range of infiltration rates that can occur in the general housing stock. Opening the house up would not have been practical, given the low outside temperatures experienced in Fresno during the winter. Therefore, we used a number of different techniques to manipulate both the infiltration rate and the temperature gradient between inside and outside of the residence, attempting to explore the infiltration driving force diagram shown in Fig. 2. This diagram depicts a range of values of air change and temperature gradients, and the conditions in a residence that will produce these values. The term float refers to a closed house with no additional forcing factors. (A zero value of $\Delta \mathrm{T}$ corresponds to the difference between the house with no HVAC conditioning and the outdoors.) A house with open doors or windows is termed simply "open." To move from naturally produced infiltration conditions to larger values for $\mathrm{ACH}$ required forcing additional air into the house by mechanical means. 


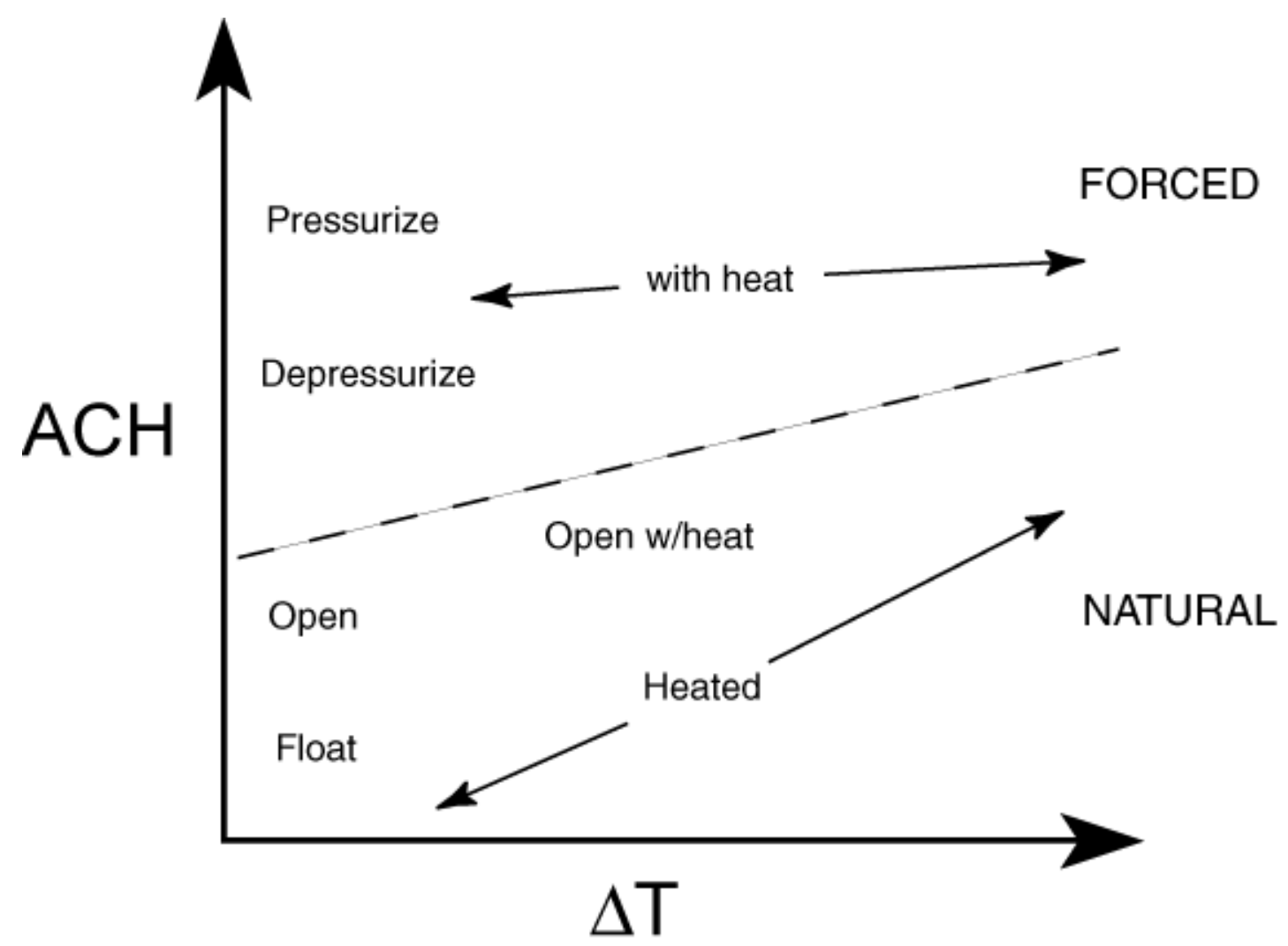

Figure 2. A schematic of the range of infiltration rates $(\mathrm{ACH})$ and indoor/outdoor temperature differences that we explored during the winter intensives. The boundary between "forced" and "natural" demarks higher values of $\mathrm{ACH}$ that could only be achieved by mechanical means. See the text for a description of the terms used to describe different conditions.

For our research house, the temperature was controlled by using the house heating system using three nominal settings - no heat, a lower heating setting $68 \mathrm{~F}(20 \mathrm{C})$, and a higher heating setting $78 \mathrm{~F}(26 \mathrm{C})$. We utilized two methods to raise the infiltration rate into the forced regime. The first made use of the fan over the kitchen range, which depressurized the building interior and increased infiltration rates to between 1 to $2 \mathrm{ACH}$. The second involved the use of a fan mounted in the master bedroom window, which was part of a HEPA filtration system, with the filter removed. This fan pressurized the house and provided large values for the infiltration rate, in the range of 4 to $6 \mathrm{ACH}$. It is worth mentioning that significant levels of nitrate aerosol were only observed inside the house at these high infiltration rates during the winter. These conditions correspond to very short residence times.

\section{Semi-Continuous Measurements of PM-2.5 Nitrate, Sulfate and Carbon}

PM-2.5 nitrate, carbon and sulfate were measured with 10-minute time resolution using the integrated collection and vaporization method of Stolzenburg and Hering (2001). This method collects PM-2.5 particulate matter by humidification and impaction onto a $1 \mathrm{~mm}$ diameter spot on a metal substrate. The sample is then analyzed by flash-vaporization and quantitation of the evolved vapor compounds. Nitrate concentrations are measured using low-temperature vaporization in a nitrogen carrier gas with quantitation of the evolved vapors using a chemiluminescent monitor equipped with a molybdenum converter to reduce higher oxides of nitrogen to nitric oxide. Sulfate and carbon analyses are performed using high-temperature 
heating, with analysis of the evolved sulfur dioxide by uv-fluorescence and carbon dioxide by nondispersive infrared absorption.

Indoor and outdoor measurements were performed simultaneously using a four-cell system. One pair of cells was used for nitrate measurements. A second pair was used for the combined measurement of carbon and sulfate. The outdoor nitrate cell and outdoor sulfate-carbon cell were housed indoors inside a box that was ventilated with outdoor air to maintain near-outdoor temperature at the point of sampling. Outdoor particles were sampled from a height of $3 \mathrm{~m}$ through a $9 \mathrm{~mm}$ diameter aluminum sampling line that was surrounded by a $86 \mathrm{~mm}$ duct through which the box ventilation air was drawn. This protected the sampling line from solar heating and temperature changes in the room.

The indoor system sampled directly from the room at a height of $1.5 \mathrm{~m}, 0.6 \mathrm{~m}$ from the wall. The outdoor collection cell box was situated near the indoor sampling cells, with the $\mathrm{NO}_{\mathrm{x}}, \mathrm{SO}_{2}$ and $\mathrm{CO}_{2}$ analyzers in between. The analyzers and flash vaporization electronics were shared between the indoor and outdoor cells. Particles were collected simultaneously, and analyzed sequentially. Collection times were $8 \mathrm{~min}$, and analysis times were $2 \mathrm{~min}$, to give an overall cycle time of $10 \mathrm{~min}$.

For both the indoor and outdoor systems, coarse particles were removed using an impactor with a cutpoint at $2.5 \mu \mathrm{m}$. Interfering vapors were removed using an activated carbon, multicell denuder. The airstream was split below the denuder, with $1 \mathrm{~L} / \mathrm{min}$ each for nitrate analysis and one for sulfate and carbon analysis. Each flow was humidified, then particles were collected by impaction and assayed in place by rapid heating of the substrate and analysis of the evolved vapors. The temperature and relative humidity of each sample stream were measured immediately above each of the four collection cells.

The systems were calibrated using aqueous standards applied directly to the collection substrate and flash-analyzed. Additionally, the span of the gas analyzers were checked using calibration gases supplied by Scott Marrin. Field blanks were determined by sampling filtered air. System performance was monitored through several automatically recorded parameters including sample flows, cell pressure during analysis, analysis flash voltage and flash duration.

\section{Ion Chromatograph System for the Measurement of Soluble Atmospheric Gases:}

An ion chromatograph (IC) system was developed to measure soluble gases indoors and outdoors at the Clovis field site. In this part of the study, ammonia and nitric acid are the primary gas phase compounds of interest. The IC analysis system consists of three subsystems:

a) denuders to collect water-soluble gases from the air,

b) concentrator columns to accumulate the dissolved gases in ionic form, and

c) anion and cation IC systems to measure the ions formed by the dissolved gases.

The goal of this system is to obtain a sum of indoor and outdoor reduced nitrogen (ammonia) and oxidized nitrogen (NOy) to aid in the understanding of gas-to-particle conversion, transformation, and deposition as outdoor air enters a building. The gas measurements provided by the IC system are a crucial component, when correlated with the house ventilation characteristics, to gain insight on the physical and particularly the chemical processes that occur during infiltration and within the indoor environment. 
The denuders are $0.6 \mathrm{~cm}$ o.d. by $70 \mathrm{~cm}$ long Pyrex tubes which are lightly etched on the interior surface to evenly distribute the flow of water. A peristaltic pump flows water at a rate of 0.8 $\mathrm{mL} / \mathrm{min}$ into a PTFE fitting at the top of the tube. The water flows down the tube and is isolated from the air flow by a phase separator at the bottom of the tube. Air is pulled through the tube in a concurrent-flow arrangement with a diaphragm pump. A critical orifice maintains the air flow rate at $1.04 \mathrm{~L} / \mathrm{min}$, which provides $0.5 \mathrm{sec}$ contact time with the water film. Identical systems are used indoors and outdoors. The outdoor denuder was fitted with a heating system for operation at temperatures below freezing. A cyclone could be attached to the outdoor denuder inlet for operation during foggy conditions.

A peristaltic pump collects the water at the bottom of the phase separator on the denuder and pumps it to the concentrator columns. Flow from the peristaltic pump is split and directed through separate anion and cation concentrator columns (Dionex) and is balanced with needle valves downstream of the columns. The flows from the concentrator columns are collected to determine the actual volume of liquid that flows through each column. The system was operated so each column accumulated ions for 28 minutes, followed by 2 minute injections into the IC system.

Separate anion and cation IC systems were used so that anions (nitrate ion from nitric acid) and cations (ammonium ion from ammonia) could be analyzed simultaneously. The injection and analysis cycle was completed in 15 minutes, allowing four measurements per hour (alternating between indoor and outdoor measurements). The cation system provides measurements of ammonium ion from dissolved ammonia, and the anion system provides measurements of nitrite ion (from nitrous acid), nitrate ion (nitric acid) and sulfate ion (sulfur dioxide).

The collection efficiency of the denuders was tested using dilute mixtures of ammonia in nitrogen and two denuders connected in series. No breakthrough into the downstream denuder was observed with gas flow rates of 1.0 to $1.9 \mathrm{~L} / \mathrm{min}$ and water flow of $0.8 \mathrm{~mL} / \mathrm{min}$. In the field, the denuders were always operated with air flows of $1.04 \mathrm{~L} / \mathrm{min}$. The denuders have very close to unity collection efficiency for soluble gases at the operating conditions used in the field.

The system was operated in a colleague's laboratory in the Chemistry Department of the University of California, Berkeley to perform a gas phase nitric acid calibration and assess the response to gas phase nitrogen dioxide. The nitric acid calibration was in good agreement with liquid calibrations, and nitrogen dioxide did not noticeably interfere with the nitric acid measurement. The method reported by Lee and Schwartz (1981a, 1981b) was used to estimate the amount of nitrogen dioxide absorbed by denuders.

The system was typically calibrated by bypassing the denuders and flowing aqueous solutions containing known concentrations of the ions of interest into the concentrator columns. This method was the only practical way to calibrate the system in the field. The IC system response to a given concentration of an ion is influenced by a number of factors, including the concentration and flow rate of the carrier (eluent) solution and the system operating temperature. While we attempted to hold these parameters constant, some variation occurred. Consequently, calibrations of the system were performed periodically. Before or after each field deployment, the two denuders were positioned side-by-side outdoors, and measurements were performed over several hours to insure that the two collection systems agreed with one another. 
After the intensive field measurements, we used the calibration measurements to develop a system response versus time curve for each of the ions of interest and completed a preliminary analysis of the field measurements. The data are under review to correct for system drift, to eliminate measurements collected when parts of the instrument malfunctioned, and to insure that the proper calibration is used. We are preparing indoor and outdoor data files with concentration versus time for ammonia, nitric acid, sulfur dioxide, and nitrous acid.

\section{Filter-Based Carbon Analyses:}

Quartz filters were used during the intensive study periods to measure integrated carbon concentrations of both outdoor and indoor air. The filters were loaded in pairs, with a front filter collecting the particles followed by a filter placed immediately behind this one, termed the back filter, to quantify any artifacts in the total carbon measurement due to gas absorption or particle devolatilization. The thermal Evolved Gas Analysis (EGA) method has been used to measure the total carbon (TC) content of the quartz filters. In EGA, a portion of the filter is heated at a

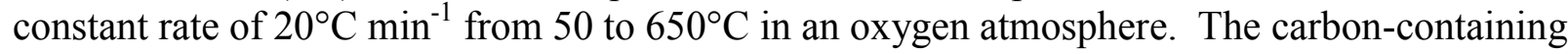
gases that evolve from the sample are converted to carbon dioxide using a catalyst which gas is subsequently measured using a nondispersive infrared analyzer. By careful analysis of the resulting plot of carbon dioxide versus temperature, called a thermogram, the carbon can be differentiated into organic (OC) and black (BC) carbon components.

Of the 140 quartz filters collected during the Dec/Jan field campaign, 130 have been analyzed. Previously, 80 of the 100 filters collected during the Oct sampling period were analyzed using the EGA method. In addition, light attenuation measurements were made for all loaded quartz filters (i.e., the front filters of the tandem filter pairs). The attenuation of light by a sample is used as a measure of the $\mathrm{BC}$ content of the collected particulate matter. The estimates of $\mathrm{BC}$ using this technique are necessary because it is often difficult to differentiate between $\mathrm{OC}$ and $\mathrm{BC}$ using only EGA since some of the $\mathrm{OC}$ co-evolves with the $\mathrm{BC}$ during the heating of the sample. A few samples have been reserved for treatment with acetone to extract organic compounds prior to thermal analysis. The removal of some of the organic material should allow better determination of $\mathrm{BC}$. The solvent extracted estimates of $\mathrm{BC}$ will be compared to those determined by light attenuation.

\section{TASK 2: CONTROLLED EXPERIMENTS IN RESEARCH HOUSE: RESULTS}

\section{Indoor and Outdoor Nitrate and Sulfate}

Nitrate, sulfate and carbon were measured with ten-minute averaging times using the Integrated Collection and Vaporization System described above. Separate cells were used for simultaneous indoor and outdoor measurements. At the outset and the close of the fall study period, the indoor and outdoor cells were compared by sampling at the same location. For a 24-hr period beginning at 1900 on August 22, 2000, both sets of cells were sampled from inside the study house. During this time the study house was well ventilated to provide sufficient sample concentration. At the end of the study period, on October 20, 2000 from 1330 to1730, the cells were compared by configuring the inlets of both systems to sample from the ventilated box. Results for nitrate and sulfate are shown in Fig. 3. We find excellent agreement between the two nitrate cells at the beginning of the measurement period. At the end of the period the two cells are well correlated, but the inside cell read about $20 \%$ lower. Recall that this configuration had the indoor cell 
drawing sample from the ventilated box of the outdoor cell. During the comparison, the temperature between the two cells slowly drifted apart as the outdoor temperature fell. This temperature difference, while slight, could cause the lower reading from the inside cell. However, the overall difference between indoor and outdoor measurements is much greater than this discrepancy. For sulfate, the correlations between the two cells were weaker at the beginning of the study when concentrations were low.

Sulfate and nitrate profiles are shown for the fall study period in Fig. 4. The most remarkable feature is that a larger fraction of the outdoor sulfate is found indoors when compared to nitrate. The indoor nitrate values are consistently much lower than outdoors, rising only during periods of maximum ventilation in the afternoon and evening of October $18^{\text {th }}$ and $19^{\text {th }}$. The peak indoor sulfate concentrations are lower, more rounded and displaced later in time than those measured outdoors. This behavior is in accordance with expectations for non-steady state transport across the building shell.

For nitrate, we have duplicate measurements of ambient levels at the CARB monitoring site in Fresno, located $5 \mathrm{~km}$ to the southwest of the study house. Comparisons between these measurements are shown in Fig. 5. Both the concentrations and the time profiles for outdoor nitrate at the house are similar to those at the central monitoring site. Both sites see similar morning concentration maxima in nitrate, although the afternoon maxima tends to be shifted later in time at the Clovis house. This is most dramatic on August 25, when both sites see the morning nitrate peak at 9am, but the second maxima occurs at noon on the central site, and at 1:30 pm at the Clovis house. The indoor concentration of nitrate shows a corresponding small maxima $20 \mathrm{~min}$ later, at $1: 50 \mathrm{pm}$. While on average these time shifts do not influence the observed daily concentration, they could be important when interpreting the data for human exposure using time/activity data. Similarly, the time lag in concentration changes from outdoors to indoors, and in our example from the central monitoring site to the study house, is important to the interpretation of indoor - outdoor concentration relationships. The data indicate that on these short time scales, a simple indoor - outdoor concentration ratio may not be a good descriptor of the concentration relationship. 
Both Cells Sampling Inside, High Ventilation $(8 / 22-8 / 23 / 00)$

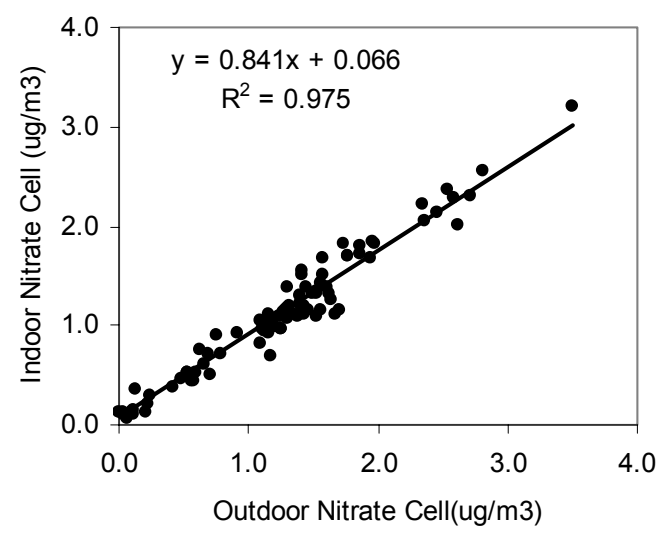

Both Cells Sampling Inside, High Ventilation $(8 / 22-8 / 23 / 00)$

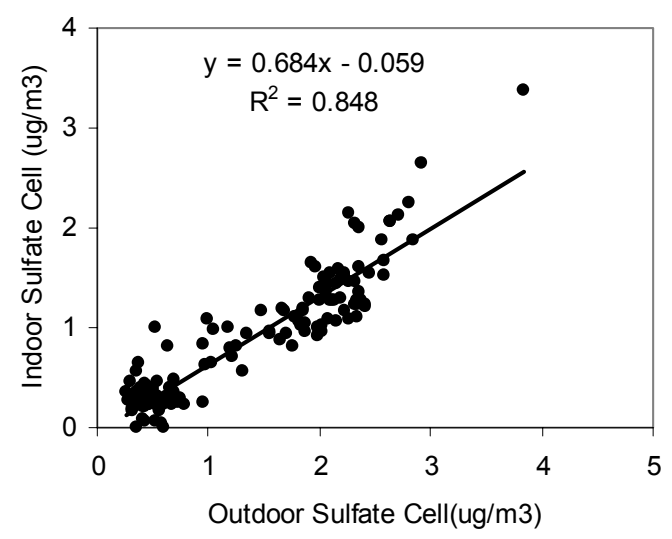

Both Cells Sampling From Ventilated Box $(10 / 20 / 00)$

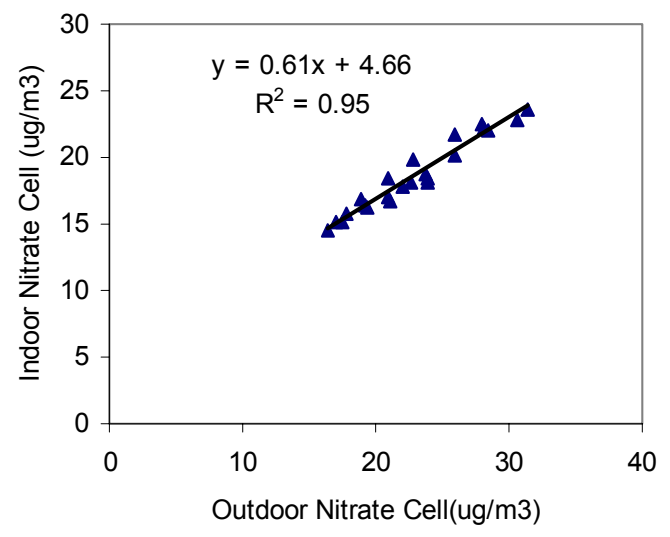

Both Cells Sampling From Ventilated Box $(10 / 20 / 00)$

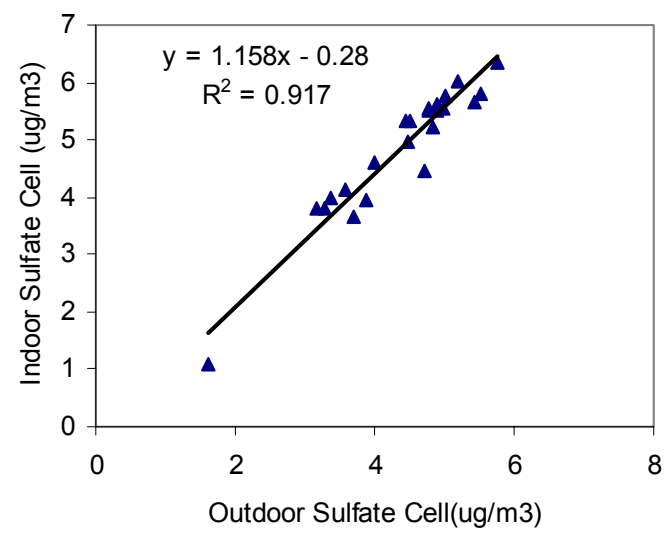

Figure 3. Comparison of Indoor and Outdoor sampling cells for nitrate and sulfate when sampling the same air. For August 22-23, 2000,both indoor and outdoor systems sampled from inside the room. On October 20, 2000, both systems sampled from the ventilated box. 

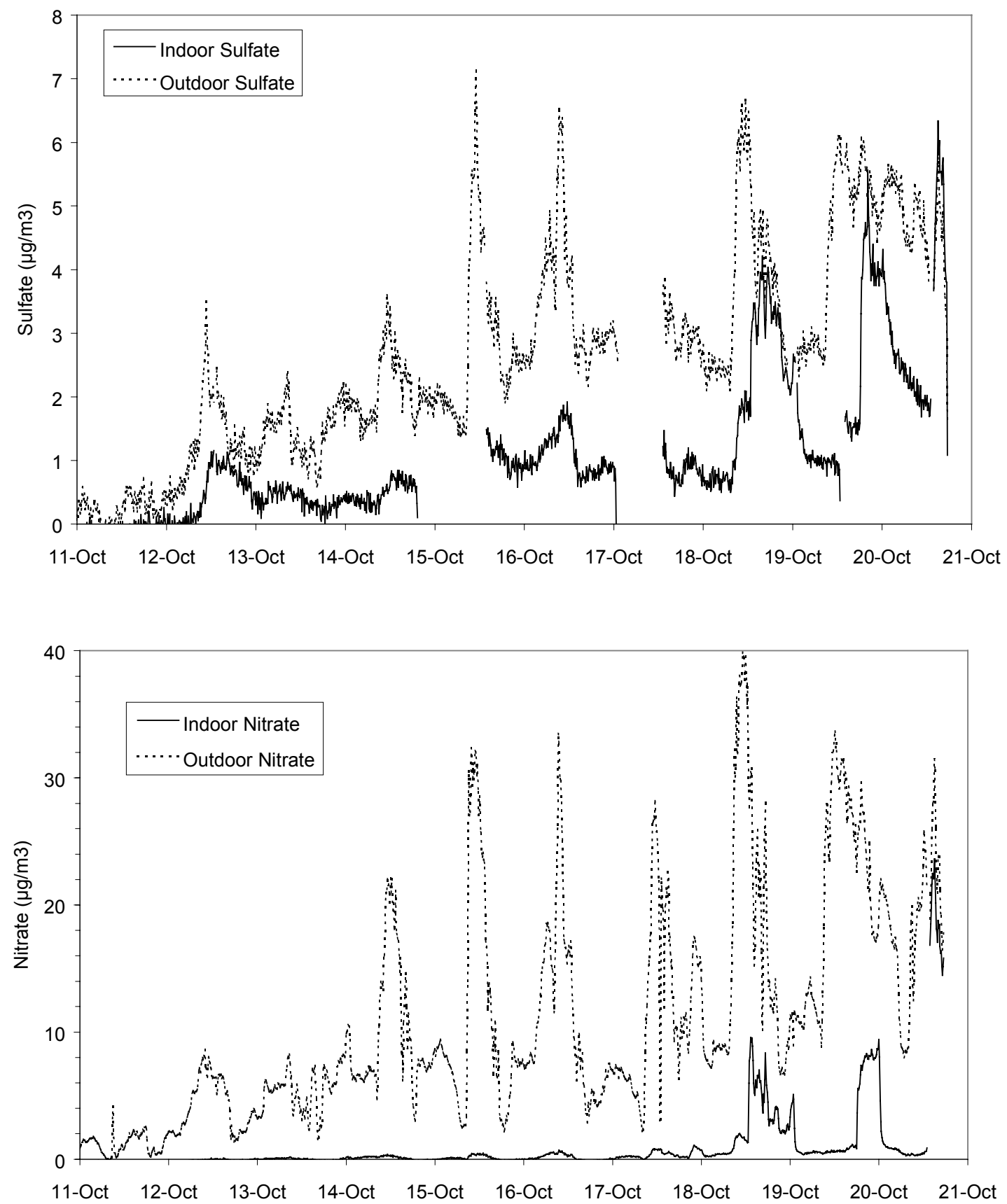

Figure 4. Indoor and outdoor sulfate and indoor and outdoor nitrate profiles at the Clovis Study house during the fall, 2000 , intensive. 


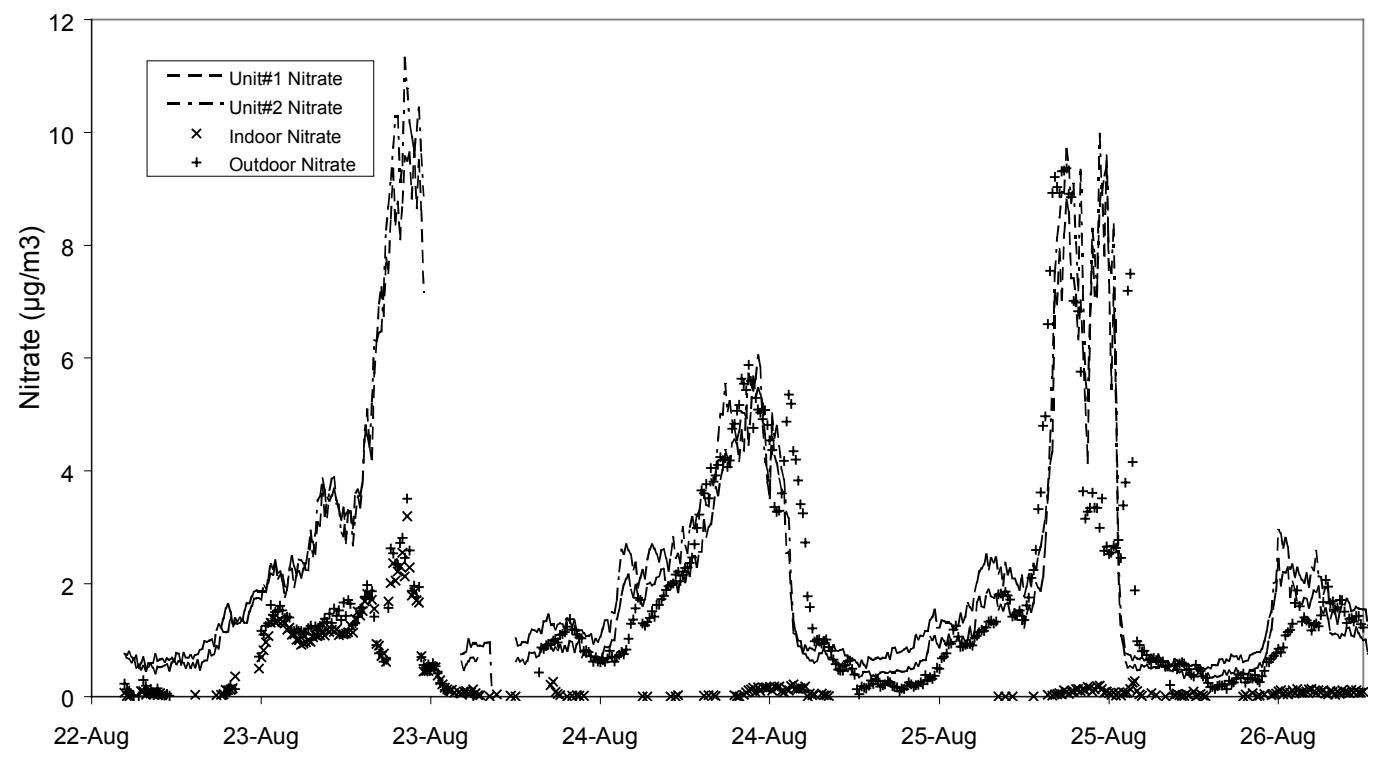

Figure 5. Comparison of nitrate profiles at the Clovis Study House to that measured at the ARB monitoring station in Fresno (labeled Unit \#1 and Unit\#2), located approximately $5 \mathrm{~km}$ to the southwest. Data through August 23 at 1900 are for both cells sampling from inside the house. Data starting August 23 at 10 pm are indoor, outdoor measurements.

\section{Ion Chromatograph System for the Measurement of Soluble Atmospheric Gases:}

The preliminary ammonia measurements from the fall intensive period in October 2000 are shown in Figure 6. The indoor and outdoor ammonia data were averaged by day (midnight to midnight) and plotted. Rainy conditions at the beginning of the period suppressed both indoor and outdoor ammonia. Instruments problems prevented collection of significant data on 17 October. The plot show that the indoor average ammonia concentration is always higher than the outdoor average ammonia concentration. The difference between indoor and outdoor concentration varies widely. 


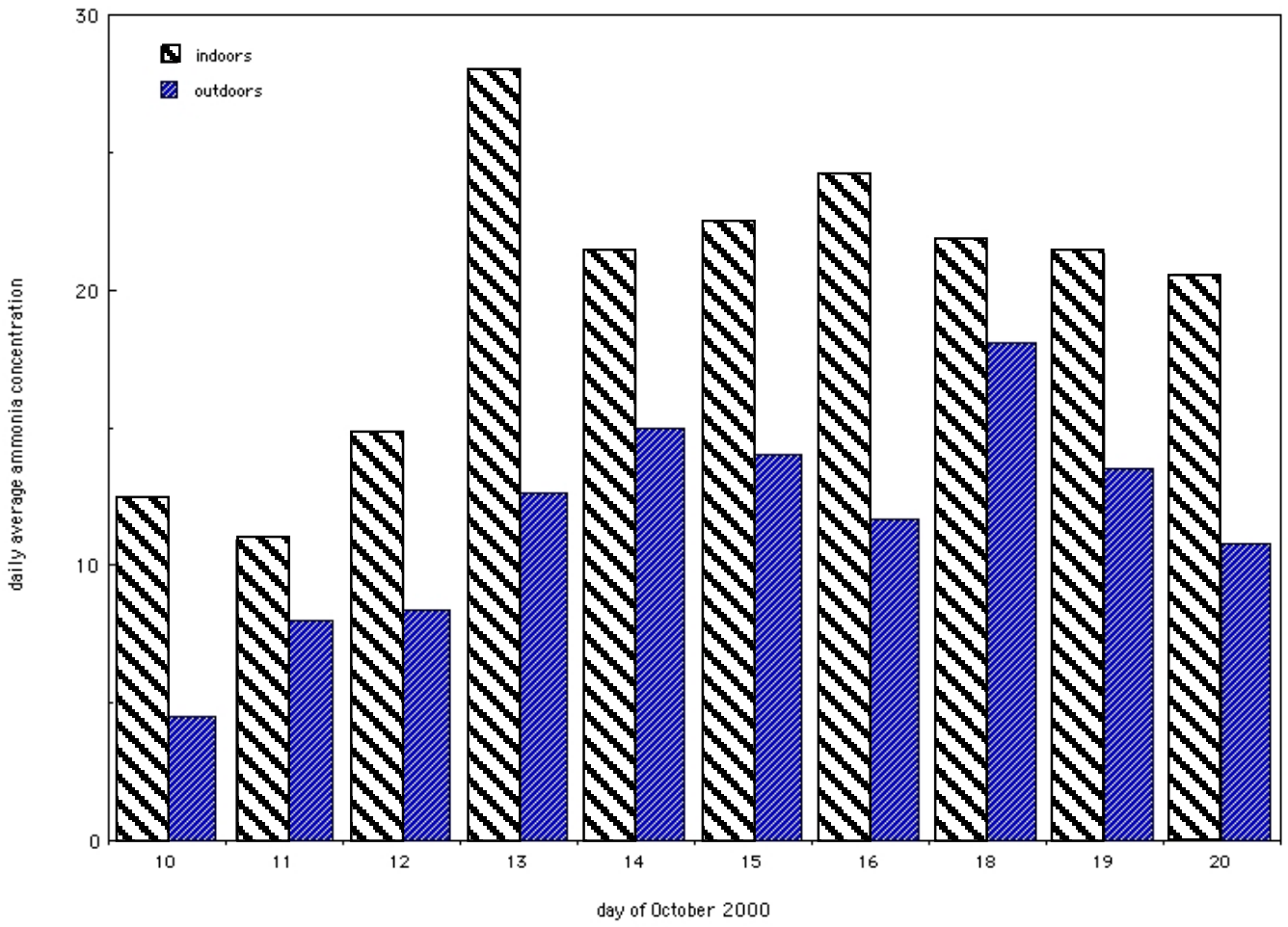

Figure 6. Average daily ammonia concentration in ppb calculated from midnight to midnight for both indoors and outdoors during the October, 2000 field intensive.

As might be expected, indoor concentrations of the gaseous compounds under study were much less variable than their respective outdoor concentrations. The following are some general observations from our measurements:

- The indoor ammonia concentration is almost always higher than the outdoor ammonia concentration.

- Nitric acid and sulfur dioxide concentrations were almost always less than 1 ppbv, as would be expected from the high ammonia concentration observed.

- If the source of the excess (compared to outdoors) indoor ammonia is particulate matter, there is not an increase in the concentration of the associated acidic species (nitric acid or sulfur dioxide).

- During October, the average outdoor concentrations of nitric acid and sulfur dioxide are higher than the average indoor concentrations.

- The average nitrous acid (HONO) concentration indoors is higher than the outdoor concentration. This is not unexpected since photolysis by sunlight reduces outdoor daytime nitrous acid to near zero.

The large measured difference between ammonia and either nitric acid or sulfur dioxide can be used to address the concern that the denuders may be collecting soluble particles as well as soluble gases. If a significant amount of ammonium-based particles were collected by the denuders, the concentration of ammonium ion would be closer to that of nitrate or sulfate ion. 
The Desert Research Institute is performing NOx measurements at the District's First Street site, and their outdoor NOx data, along with the indoor NOx measurements from the particle nitrate system, may help in understanding the nitrous acid chemistry.

\section{Combining the High-Time Resolution Particulate and Gaseous Measurements:}

One focus of this research study was to coordinate near real-time measurements of gases and particles using some of the newest advances in measurement technologies. Information obtained using these new technologies is critical to improving our understanding the chemical transformation of particulate matter upon entrance into a residence. The aerosol of primary interest for chemical transformation is ammonium nitrate, which comprises a substantial mass fraction of PM-2.5 in California and in other parts of the West. In the atmosphere, ammonium nitrate is in equilibrium with gas phase ammonia and nitric acid. Upon entry into the house, changes in temperature and the gas phase concentrations of ammonia and nitric acid shift this equilibrium, resulting in the production of more particulate or the dissociation of existing particulate ammonium nitrate. In the indoor environment, the gas phase concentration of ammonia and nitric acid is highly affected by deposition to surfaces.

The two previous sections have described the development and performance of two important instruments needed to investigate ammonium nitrate chemistry. By providing highly timeresolved measurements, we are able to investigate the dynamics of the chemistry and its dependence on housing characteristics in ways that simple integrated filter measurements do not allow. Some initial results from the integrated collection and vaporization system (nitrate) and the automated IC system are shown in Fig. 7. The indoor environment was manipulated for each of the four 12-hour periods as follows: 1) air exchange rate ACH-4 h ${ }^{-1}$ with heat off, 2) ACH-5 $\mathrm{h}^{-}$ ${ }^{1}$ with heat on, 3) ACH- $0.3 \mathrm{~h}^{-1}$ with heat off, and 4) ACH-1 $\mathrm{h}^{-1}$ with heat off. Note how well correlated the outdoor ammonia and ammonium nitrate measurements are, particularly on Jan 20th. The effect of indoor conditions on phase change is well illustrated by the transition from period 1 to 2 . When the heat is turned on there is a sharp decrease in indoor ammonium nitrate particle concentration and an increase in indoor gas phase ammonia, indicating a shift from particle to gas phase. 


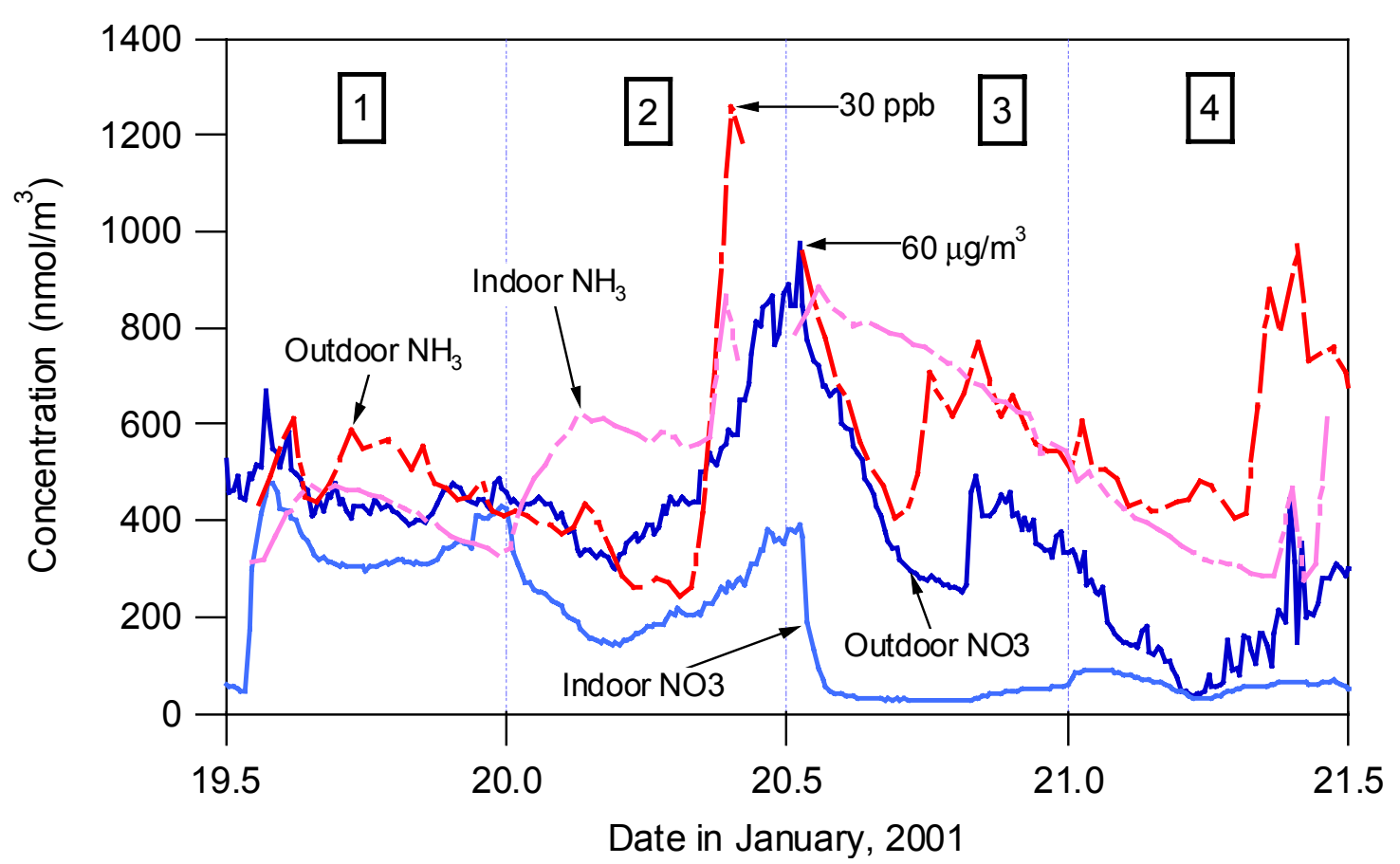

Figure 7: High time resolution measurements of the concentration of both ammonium nitrate particles and gaseous ammonia outdoors and within the residence.

\section{Filter-Based Carbon Analyses:}

Figures 8 and 9 compare indoor and outdoor average concentrations of Total Carbon and Black Carbon, respectively, during each sample period. Computations are based on a sample time of $11.5 \mathrm{~h}$ and an average sample flow rate of $12 \mathrm{~L} \mathrm{~min}^{-1}$. Estimates of TC concentration have not yet been corrected for sampling artifact (i.e., concentrations are based only on the mass of carbon collected by the front filter of the tandem filter pair). BC concentrations are based on light attenuation measurements made with each filter prior to (when loaded) and after (when clean) EGA. The trend toward elevated concentrations of $\mathrm{TC}$ and $\mathrm{BC}$ during wintertime is evident in both figures. Figure 10 shows four carbon thermograms produced by EGA. A thermogram is a plot of the amount of carbon that evolves from the sample as it is heated during analysis. It is similar to a chromatogram, except that in EGA organic compounds are not individually resolved but co-evolve as compound groups with similar thermochemical properties. The area under the thermogram curve is proportional to the carbon content of the sample. In Fig. 10, outdoor thermograms are compared to indoor thermograms to illustrate an interesting feature that is representative of most samples collected in October. Backup filters are used to estimate the amount of organic gases that become adsorbed to the front filter during sampling. The adsorption of organic gases is referred to as the positive artifact. Experience tells us that the first peak in the thermogram (an indication that some organic material evolves at low temperature) is usually a result of the positive artifact. In the case of the indoor sample, the first peak has similar area and evolution temperature in both front and back filter thermograms. Therefore, we conclude that the backup filter is a good measure of the positive artifact and that the first peak of the front filter's thermogram should not be included to estimate airborne organic particulate matter concentration. The same cannot be said of the outdoor sample because it is clear that the 
carbon content of the backup filter is not an accurate measure of the carbon that evolves at the lowest temperatures from the corresponding front filter.

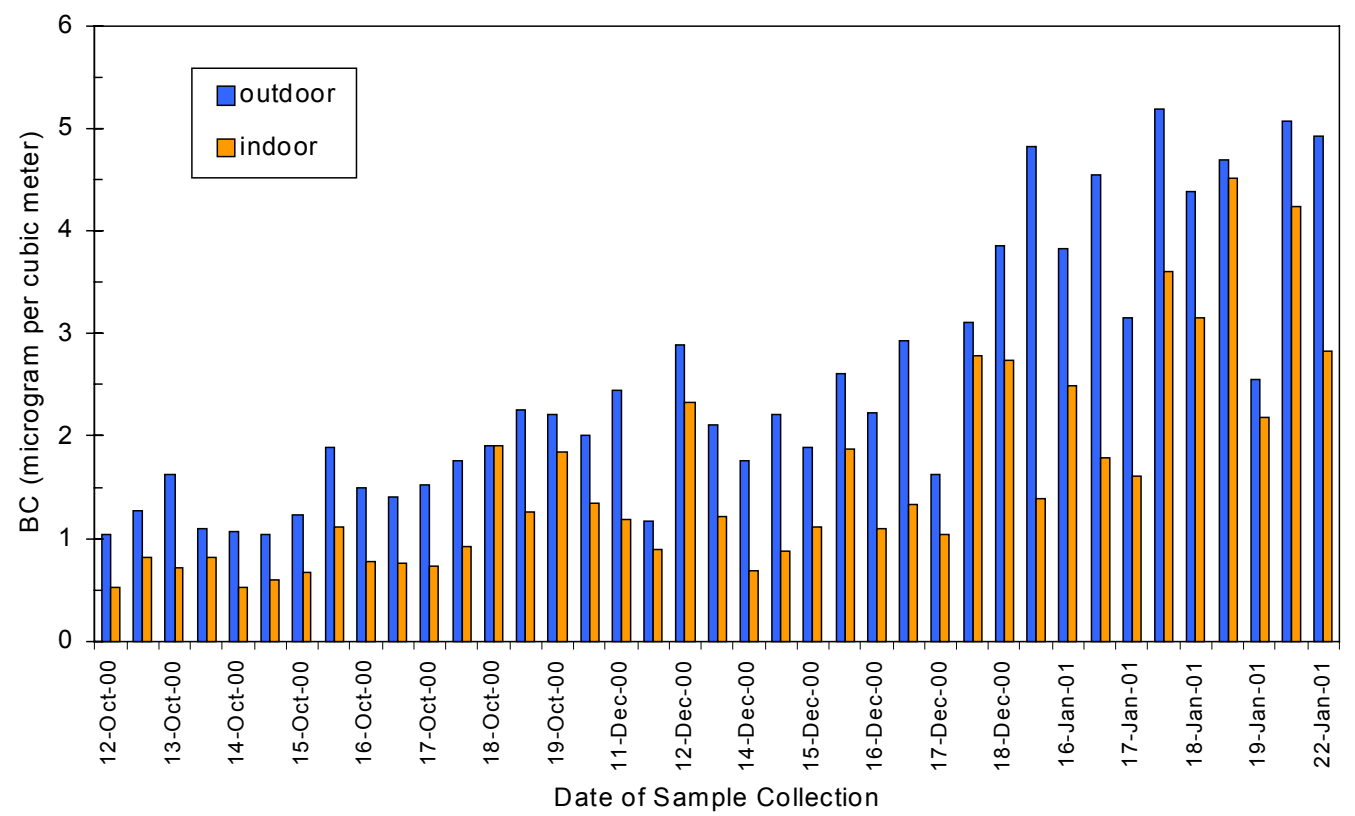

Figure 8. Outdoor and Indoor Average Total Carbon (TC) Concentrations based on the front quartz filter, not corrected for sampling artifact.

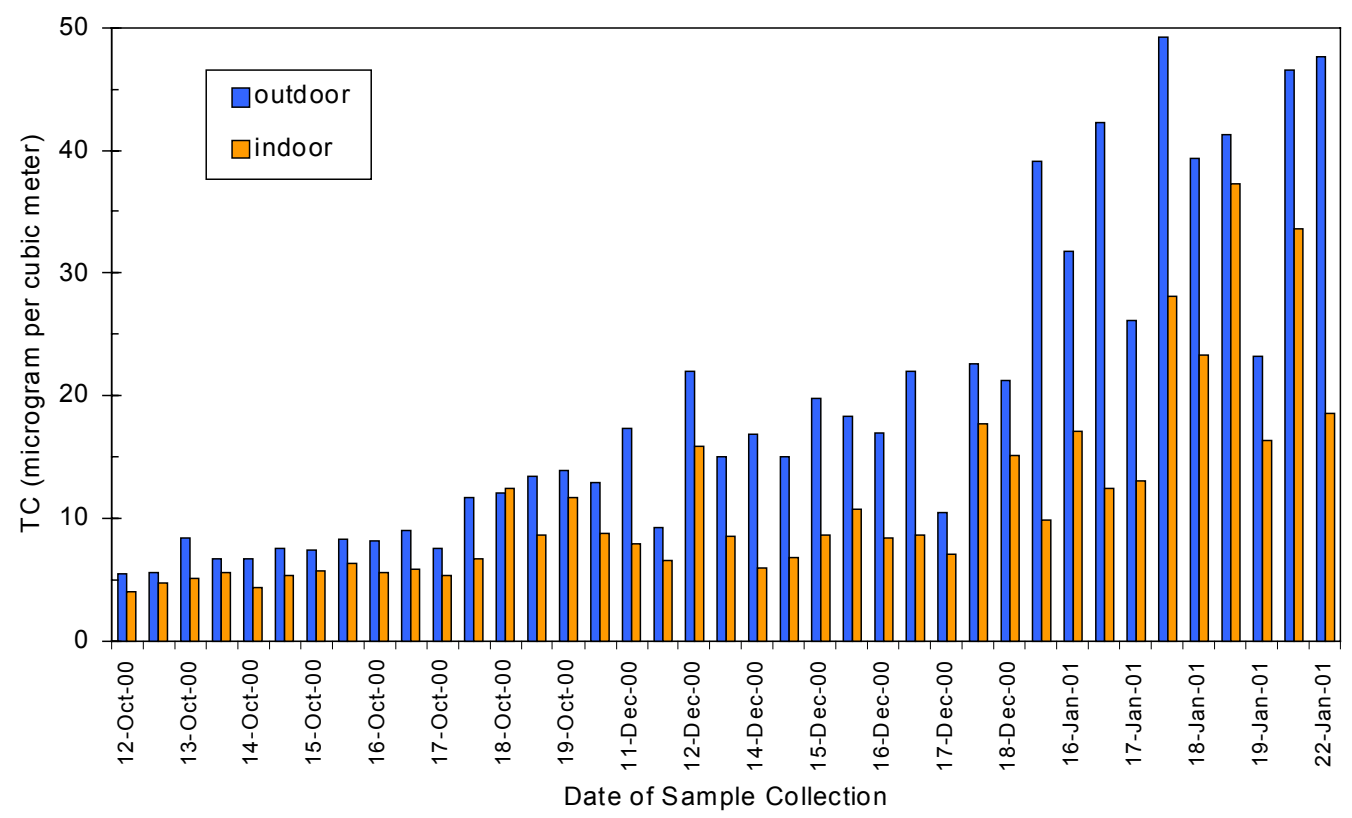

Figure 9. Outdoor and Indoor Average Black Carbon (BC) Concentrations based on light attenuation by particulate deposits on quartz filters. 

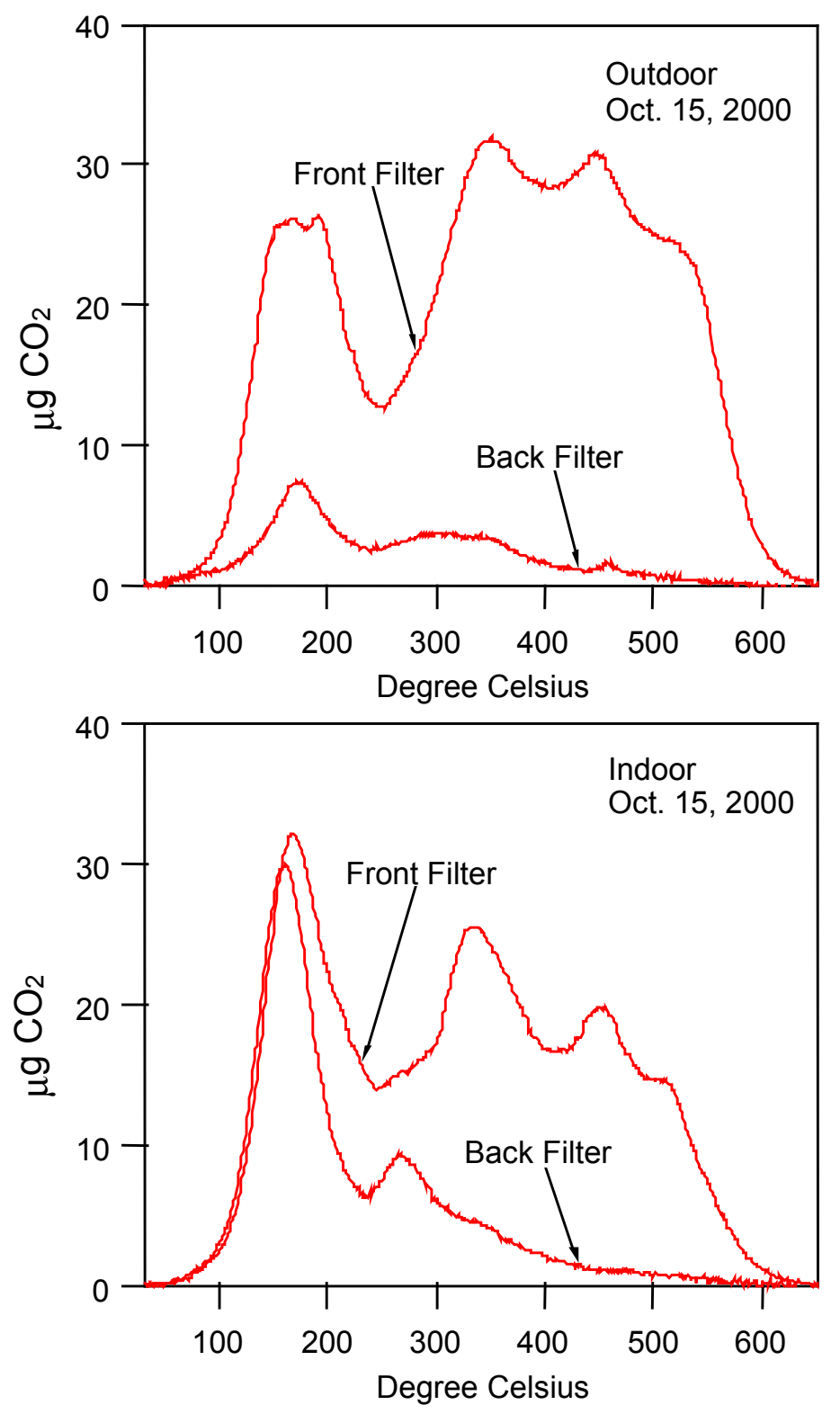

Figure 10. EGA thermograms for the outside and inside set of quartz filters sampled from 1:30 PM on Oct. 15 to 1:00 AM on Oct. 16, 2000.

Consequently, the correction for the positive artifact is not straightforward for the outdoor sample. It may be that the backup filter underestimates the mass of gases adsorbed on the front filter. Examination of Teflon filters, collected in parallel with the quartz filters in Dec/Jan, is underway to help clarify this. Teflon filters, compared with quartz filters, have a chemically inert surface and do not appreciably adsorb organic gases. While the Teflon filters decompose prior to completion of the thermal analysis, they can provide useful information at the lower thermogram temperatures. In addition, carbon thermograms of samples collected in Dec/Jan will 
be examined to determine if such a front/back filter trend existed during periods of elevated particulate matter concentrations.

\section{Collaborative Research at the Clovis House:}

A great deal of effort was expended to prepare the Clovis house for the extensive particle and house characterization necessary for the project. In order to capitalize on this effort, two other research groups at LBNL have used the house after our intensive campaign to perform additional experiments to characterize the house more completely, and to explore penetration and deposition phenomena in the house using an alternate methodology. Both of these efforts will serve to improve our modeling efforts, so we present a brief summary of these activities.

House Characterization: The physical characteristics of the house have been measured extensively. Blower door measurements, which measure the amount of air leakage under various imposed pressure differentials, have been performed on the house. This measurement is commonly used to compare the relative 'tightness' of homes. The normalized leakage (NL) of the house in Clovis is 0.65 . (Normalized leakage is the leakage area normalized by floor area and a house height factor.) The average house in California has a NL of 1.2, and the average new house has approximately 0.75 . A well-sealed new house has a NL around 0.5 , and a very tight house has about 0.25 . In addition, measurements were made of the flow through the heating system and into each of the air registers throughout the house, as well as the air exchange rate between the house and the attic and garage. This information is important for assessing the effect of use of the heater and air conditioner and possible confounding effects from particles entering the house from areas not well represented by the outdoor monitors. This work is supported by the Department of Energy, Office of Building Technologies.

Penetration/Deposition experiments: Quasi-steady state experiments were performed to determine penetration and deposition rates. This method alternates periods of constant pressurization with periods of constant depressurization using a blower door with a fan that can operate in both directions. During pressurization, outdoor air is brought indoors through a window-mounted fan, thereby eliminating the effect of penetration losses through the building shell. During depressurization, the air is drawn through cracks in the building shell and particles may experience penetration losses. Comparison between the pressurization and depressurization concentrations allows separation of the effects of deposition and penetration losses. Varying values of depressurization were used to assess the effect of airflow rate through the building cracks on penetration loss rates. This work is supported by the Department of Energy, Office of Non-Proliferation Research and Engineering. 


\section{TASK 3: MODEL FORMULATION AND PARAMETERIZATION}

\section{Penetration and Deposition:}

Two important physical factors, which influence the indoor particle concentration are losses due to surface deposition and penetration losses through the building shell. Construction of an accurate predictive model requires an understanding of not only the magnitude of these parameters, but also their variability and the causes for this variability.

Many researchers have performed experiments to study particle deposition in the indoor environment (Offermann et al, 1985; Xu et al., 1994; Byrne et. al., 1995; Thatcher and Layton, 1995; Fogh et al., 1997; Vette et al., 2001; Mosley et al., 2001, and Thatcher, et al., 2001). The results of these studies form a basis for our understanding of deposition. Measured deposition loss rates show a wide degree of variability for any given particle size. This variability is due, in part, to differences in the conditions under which deposition rates were measured, such as airflow intensity, furnishings, surface-to-air temperature differences, particle composition and shape, electrostatics, and instrumentation and measurement methods. Our understanding of the relative influence of these various environmental factors is still incomplete.

Another key factor influencing indoor exposures to particles of outdoor origin is the affect of losses due to particle filtration by the building shell. These losses are typically quantified by the use of a penetration factor, $\mathrm{P}$, defined as the fraction of particles in the infiltrating air, which pass through the building shell. Experimental data on penetration factors in actual homes is sparse. This leads to a high degree of uncertainty in the appropriate value to use for the penetration factor.

Since both deposition and penetration losses are particle size dependent and occur simultaneously, it is difficult to separate the effects of these factors in a residence. Our experimental design is such that the indoor concentration is varied over a wide range and we analyze events where deposition is the dominant loss mechanism as well as those where penetration losses dominate. A transient model employing a two-parameter fit is used to determine the combination of deposition rate and penetration factor which best fit the observed data.

A typical run started with a short period of resuspension activities followed by a period of concentration decay. The building was then pressurized using a High Efficiency Particle Absolute (HEPA) filter mounted in a window. The HEPA filter supplied the building with essentially particle free air, causing the particle concentration to drop to nearly zero. The HEPA filter was then turned off and the concentration was allowed to rebound to a steady state value. During the concentration decay period, when indoor concentrations are relatively high, losses due to deposition are large compared to gains due to particle infiltration. During the concentration rebound period, the opposite is true. Therefore, penetration and deposition losses can be effectively separated. We applied this method in both the field houses in Richmond and Clovis, CA. The very different construction of the two houses allows us to investigate the effect of building characteristics on deposition losses and penetration factors. 
Figures 11 and 12 show the penetration factors and deposition loss rates as a function of particle size obtained from the experiments performed in the Richmond field house. The difference between the optical and aerodynamic instruments is most likely due to the different methods employed by the instruments to measure particle diameter. The optical instrument uses light scattering to measure the apparent optical diameter of the particle. For non-spherical particles, the optical diameter of a particle can be significantly different than the aerodynamic diameter, which is measured using the velocity of a particle through an accelerating air stream. Analysis of the experiments from the Clovis house is in progress.

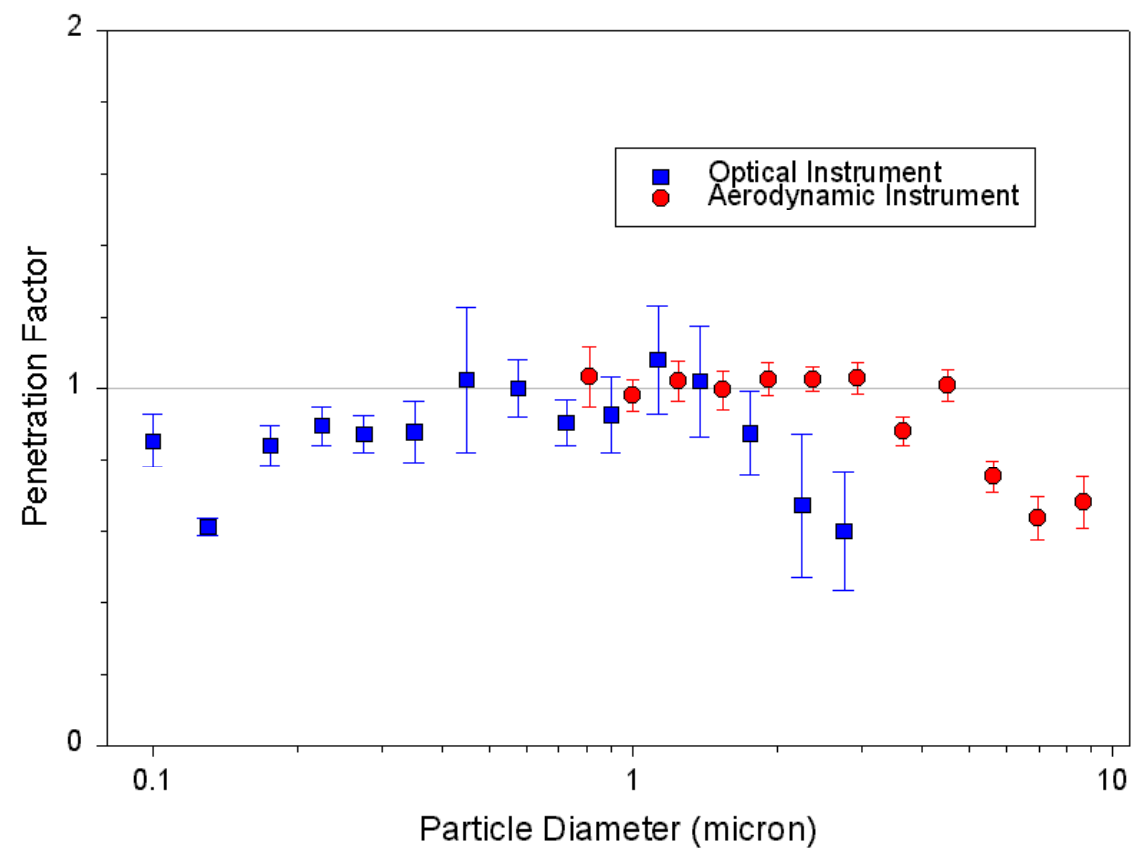

Figure 11. Particle penetration coefficient as a function of particle diameter for experiments at the Richmond field building. Error bars represent the standard error. 


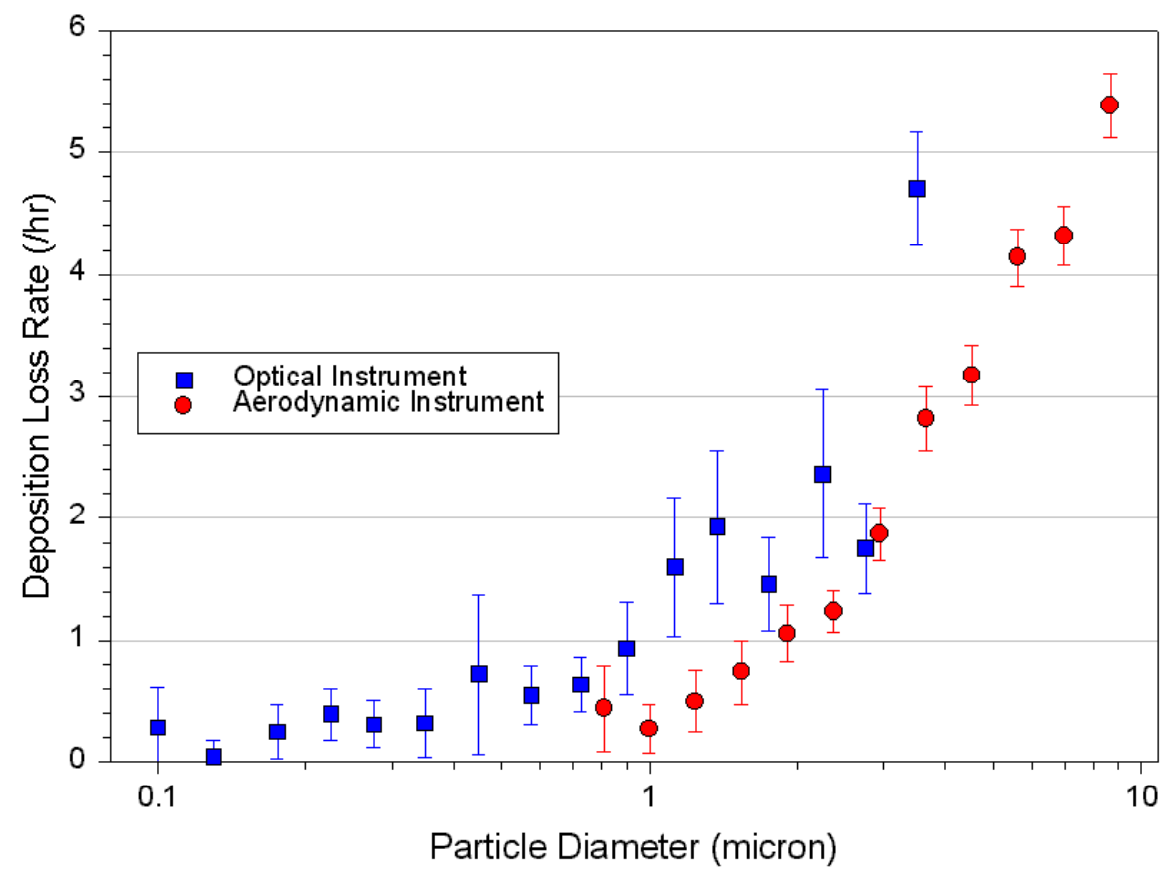

Figure 12. Deposition Loss Rates as a function of particle diameter for the Richmond field building. Error bars represent the standard error.

\section{Dynamic Behavior of the Indoor/Outdoor Particle Ratio:}

There are a number of physical factors that contribute to the distribution of indoor/outdoor ratios at a particular value of infiltration rate. One primary consideration is the time lag between changes in outdoor concentrations and response within a residence. The outdoor concentration of any particular aerosol species continually varies with time and it takes the house a period of time to respond to these changes. The response time to changes in outdoor concentrations will depend on the time scales for infiltration and particle removal. For chemically reactive species, such as nitrate, the indoor/outdoor ratio will also be a function of the conditions (e.g.

temperature, other reactant concentration) in the residence. In addition, outdoor pollutants can be local in nature (such as a neighbor mowing the grass) that generate particle plumes. The plumes do not encompass a large enough area for a long enough time to distribute uniformly across the building shell and infiltrate into the house in a predictable manner. 


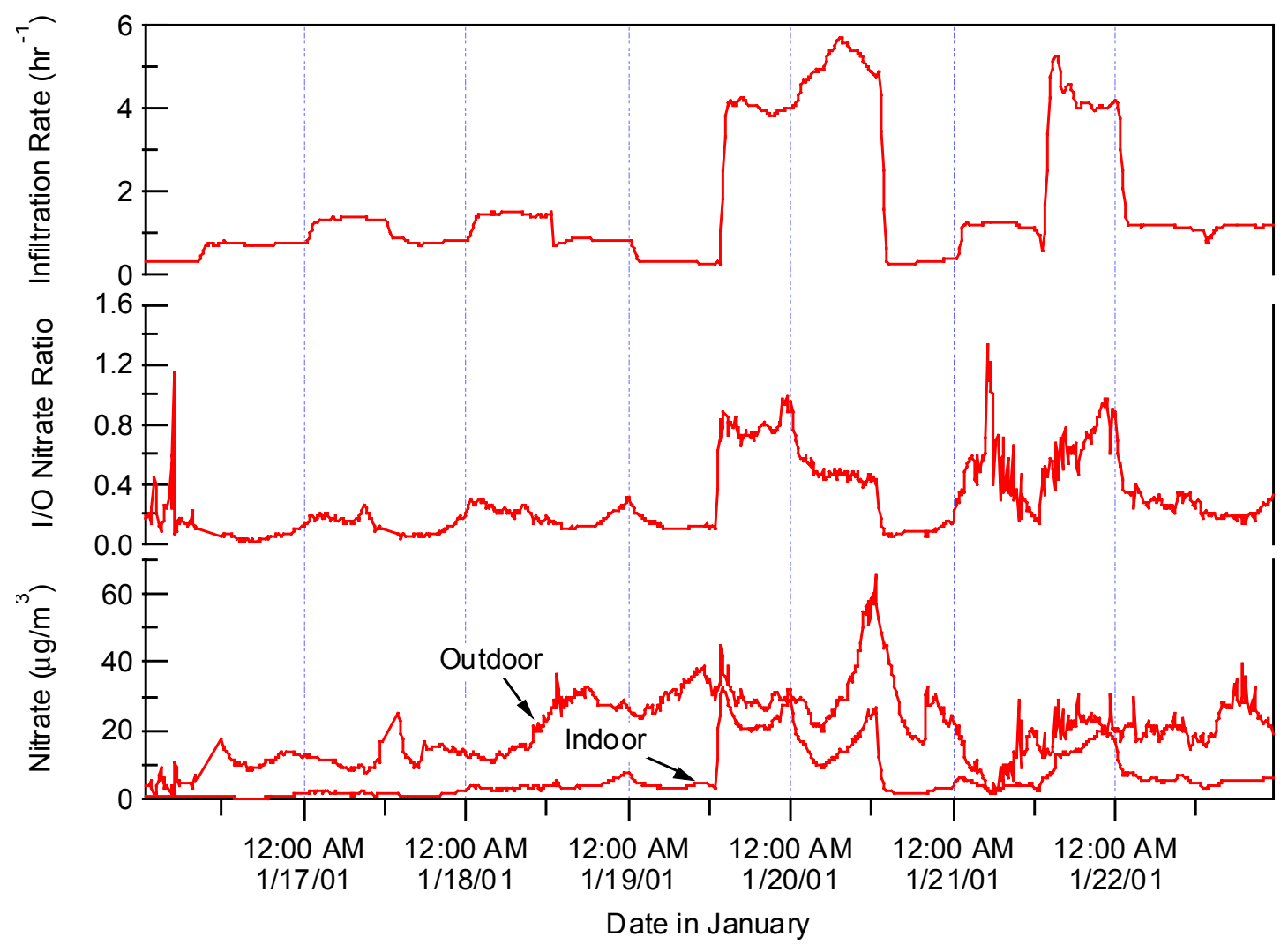

Figure 13. Outdoor and indoor particle concentrations, the indoor to outdoor nitrate concentration ratio, and the infiltration rate as a function of time for the intensive measurement period in January, 2001.

As a first examination of the real time data from the intensives, we have focused on exploring the dynamics of the ratio between indoor and outdoor levels. We are specifically interested in what we are exposed to indoors from outdoor sources. We focus on the ratio because it has been an historical focus of the "infiltration" community. Although this analysis is preliminary, some interesting observations have emerged. Figure 13 shows a plot of the nitrate data collected during part of the January intensive, along with the indoor/outdoor ratio and the infiltration rate. It does appear that, on average, higher air change rates result in a larger indoor/outdoor ratio. However, when viewed over shorter time ranges, it is clear that a range of ratios is associated with a specific value of infiltration rate. This is drastically different than many previous studies that report a single value of the indoor/outdoor ratio for a house or collection of houses in a particular geographical area. (Dockery and Spengler, 1981, Ozkaynak et al, 1996, Wallace, 1996.) These results show the strength of the near real-time particulate analysis system. 
Because the infiltration of pollutants into a structure can exhibit complex behavior, and due to the availability of our high time-resolution data, we have begun to probe the equation describing particle infiltration in more detail. A simple form of the time change in indoor particle concentration for a given size and composition particle can be written as follows:

$$
\frac{d C_{i}}{d t}=\left(C_{o} P-C_{i}\right) \lambda-C_{i} k_{d e p}
$$

where: $\mathrm{C}_{\mathrm{i}} \quad$ indoor concentration

$\mathrm{t} \quad=$ sample time

$\mathrm{C}_{\mathrm{o}} \quad=$ outdoor concentration

$\mathrm{P}=$ penetration loss factor

$\lambda=$ air exchange rate

$\mathrm{k}_{\mathrm{dep}}=$ deposition loss rate

This equation can be rearranged to express the ratio of indoor to outdoor pollutants,

$$
\frac{C_{i}}{C_{o}}=\frac{P \lambda-1 / C_{o} d C_{i} / d t}{\lambda+k_{d e p}}
$$

This formation of the equation for the ratio may help provide insight into the relative importance of various factors influencing the indoor-outdoor ratio since the major loss terms are grouped in the denominator, while the important gain term is in the numerator.

A great deal of previous research regarding particle infiltration has assumed steady state conditions, $\mathrm{dC} / \mathrm{dt}=0$, which greatly simplifies equation (1). (Alzona et al, 1979; Dockery and Spengler, 1981, Ozkaynak et al, 1996, Thatcher and Layton, 1995, Vette et al, 2001, Long et al, 2001) Our data show that this assumption is often inappropriate. Moreover, it is clear that the assumption that $C_{o}$ and $\lambda$ are constant is also often not true. To explore the time rate of change of this ratio, terms involving quantities such as the time rate of change of the infiltration rate $(d \lambda / d t)$, time derivatives of both $\mathrm{C}_{\mathrm{i}}$, and $\mathrm{C}_{0}$, and the ratio $C_{i} / C_{o}$ will be compared. We are currently using the data set to explore the relations in the dynamic form of the infiltration equation, with a goal of identifying what processes most affect the ratio and under what conditions. In addition, we are integrating the data using various averaging times to observe differences in the indoor/outdoor ratio and the dependence of this ratio on other observables such as the infiltration rate change.

\section{Infiltration model developments: application of the LBNL Infiltration Model}

Predicting average concentrations of indoor PM of outdoor origin (that are most relevant for estimates of chronic PM exposures) requires sub-models describing air infiltration rates and the indoor PM concentrations that result from infiltration and other processes. Infiltration rates can be predicted based on readily measured properties of the housing stock (e.g. leakage areas), regional meteorological characteristics, and assumptions concerning the human factors affecting building operation (e.g window and door opening, and HVAC operation). Predicting air 
infiltration rates for housing stocks representing geographical areas can arguably best be done using a probabilistic approach that explicitly incorporates the uncertainties inherent in building parameters and housing operation.

We have recently completed an initial comparison of the measured and predicted infiltration rates obtained from the Clovis field site house. The infiltration rate was measured with approximately hourly resolution using a constant release of $\mathrm{SF}_{6}$ tracer gas. The infiltration rate was modeled using the LBNL/AIM infiltration model (Walker and Wilson, 1998). The model is parameterized by building characteristics (e.g. area, volume, and leakage area), and driven by measured indoor-outdoor temperature differences and wind speed and direction.

As shown in Fig. 14, the comparison between the measured and the most probable model estimate of infiltration rate is quite good for a period in December 2000, when the house was not mechanically ventilated. In particular the model captures the diurnal variation in air infiltration rate due to temperature induced "stack effect", and partially captures the increases in infiltration rate due to wind loading on the building during the windy periods on day 356 and 357 . Some of the other artifact spikes in the measured data are due to people entering the house or introducing extra tracer gas during a change of the tracer gas supply system. Based on the good agreement between the measurements and the model we expect to be able to extend the predictive capability for infiltration rate and later indoor particulate matter concentrations to the larger housing stock.

\section{Infiltration Rate Comparison}

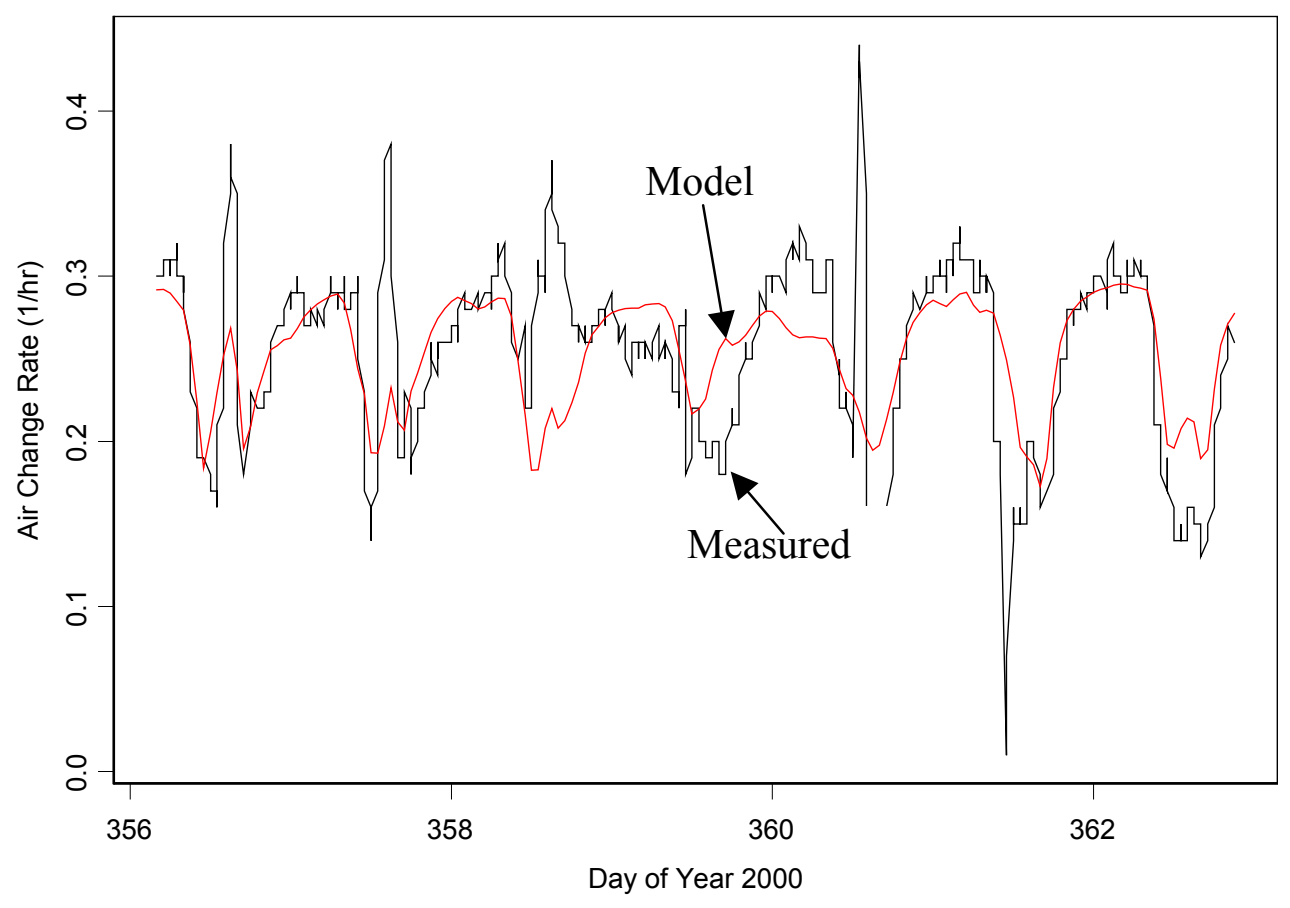

Figure 14. Measured and modeled infiltration rate for the Clovis residence. 
Completion of the infiltration rate modeling requires an explicit estimate of the uncertainty in infiltration rates and an estimate of the likely uncertainties in the indoor-outdoor PM ratio. We are presently completing the uncertainty analysis for infiltration rates based on RMS differences between the measured data and model predictions from the Clovis field site and plan to complete a first order error analysis of indoor outdoor PM ratios later this summer. Errors in the estimated indoor-outdoor PM ratio due to infiltration uncertainties will be estimated by comparing $12 \mathrm{hr}$ averaged indoor-outdoor PM ratios calculated using measured and modeled infiltration rates to drive a time dependent size conserved particulate transport model that includes characteristic PM size distributions and PM deposition rates. Once complete the infiltration rate analysis will be combined with measured indoor-outdoor ratios to test both the size conserved model and model refinements that embody physio-chemical processes relevant to nitrate particulate matter formation.

\section{CONCLUSIONS}

The goal of this project is to develop a physically-based, semi-empirical model that describes the concentration of indoor concentration of PM-2.5 (particle mass that is less than 2.5 microns in diameter) and its sulfate, nitrate, organic and black carbon constituents, derived from outdoor sources. We have established the methodology and experimental plan for developing the model. Experimental measurements in residential style houses, in Richmond and Fresno, California, are being conducted to provide parameters for and evaluation of this model. The model will be used to improve estimates of human exposures to PM-2.5 of outdoor origin. The objectives of this study are to perform measurement and modeling tasks that produce a tested, semi-mechanistic description of chemical species-specific and residential PM-2.5 arising from the combination of outdoor PM and gas phase sources $\left(\mathrm{HNO}_{3}\right.$ and $\left.\mathrm{NH}_{3}\right)$, and indoor gas phase (e.g. $\left.\mathrm{NH}_{3}\right)$ sources. We specifically address how indoor PM is affected by differences between indoor and outdoor temperature and relative humidity. In addition, we are interested in losses of particles within the building and as they migrate through the building shell. The resulting model will be general enough to predict probability distributions for species-specific indoor concentrations of PM-2.5 based on outdoor PM, and gas phase species concentrations, meteorological conditions, building construction characteristics, and HVAC operating conditions.

Controlled experiments were conducted in both the fall and winter for the Clovis house. The winter experiments, in particular, focused on methods to manipulate important house parameters like infiltration rate and temperature gradient to explore the range of conditions that would be encountered in the general housing stock. In addition to a suite of tradition aerosol, meteorological and house characterization instruments, two new instruments were developed for the study. These instruments, the integrated collection and vaporization system (IVCS) and the automated ion chromatograph system to measure soluble atmospheric gases, were crucial provide the highly time-resolved data necessary to characterize the particle infiltration dynamics.

Experimental results from the fall and winter have provided many initial insights into the important physical processes governing particle infiltration. Duplicate IVCS measures of nitrate at a site $5 \mathrm{~km}$ away show that the two locations experience similar outdoor concentration profiles, with the occasional time shift between events. The IVCS showed a larger fraction of sulfate indoors than nitrate, providing evidence that the nitrate particles undergo chemical 
transformations upon entering the residence. This observation was supported by gas measurements provided by the automated IC system, which showed that average indoor ammonia concentrations were always higher than average outdoor concentrations. Moreover, indoor concentrations of nitric acid were quite low. If the source of the higher indoor ammonia concentrations is the dissociation of particulate nitrate, then the nitric acid is quickly lost to deposition. Perhaps most exciting is the combination of the two systems, which shows that outdoor ammonia and nitrate particulate are well correlated. This data also show the effects of air change and heat on the indoor nitrate concentrations, with larger indoor temperatures leading to a decrease in indoor nitrate and an increase in indoor ammonia.

Model development based upon our experimental results has focused on three areas. An innovative experiment was designed to separate the effects of particle penetration and deposition, fitting the data with a transient model. Results presented for the Richmond house, which is quite leaky, show the resulting penetration factors to be large. The deposition results are in a reasonable range when compared with previous measurements. The real-time data from the intensives has been used to investigate the dynamic behavior of the indoor/outdoor particle ratio. The data have been examined using a simple form of the dynamic infiltration equation, which includes the effects of important parameters like penetration, deposition, and infiltration rate. Initial results show that the traditional assumption of steady state conditions cannot, in general, be made; many values of the indoor/outdoor ratio exist, particularly at low air change rates. Finally, we have been successful in predicting infiltration rates for the Clovis house using experimentally measured drivers of indoor-outdoor temperature differences and wind speed and wind direction. This ability to predict infiltration rate will important to extend the results for our one house to the larger housing stock.

The experiments that we have conducted in Clovis, turning the typical suburban house into a laboratory, have yielded an extraordinarily rich data set. While many of the individual measurements are interesting on their own, the true value comes with the combination of different techniques, as seen by the correlation of the real time gas and particle measurements. Important initial observations include the result that, with rare exceptions, there is virtually no nitrate found inside the house. This nitrate appears to dissociate into ammonia and nitric acid with the nitric acid depositing out quickly. Our initial model development has focused on what will become elements of the larger semi-empirical model to predict the concentration of outdoor PM-2.5 inside residences. Using the results of this study, we should have an excellent understanding of the important physical processes controlling the movement of outdoor particles inside.

\section{ACKNOWLEDGEMENTS}

This research was supported by the Assistant Secretary for Fossil Energy, Office of Natural Gas and Petroleum Technology, through the National Petroleum Technology Office under U.S. Department of Energy Contract No. DE-AC03-76SF00098. We are also especially grateful to the Western States Petroleum Association for providing in kind support for our research through their sponsorship of the California Regional Particulate Air Quality Study. We gratefully acknowledge the encouragement and assistance of Dr. Steve Ziman of Chevron for his many helpful suggestions. We also are grateful for the efforts of other LBNL colleagues: Dr. Richard Sextro, Dr. Lara Gundel, and Dr. Ray Dod, who contributed to this research under the 
sponsorship of the U.S. Environmental Protection Agency. We appreciate the efforts of Dr. Max Sherman and his group who measured the physical characteristics of the house, and assisted us in our use of the LBNL infiltration model. We thank Ken Revzan and Dennis Dibartolomeo for their help in data acquisition, establishing a data archive, and for assistance in other computational efforts. We thank our student assistants Emily Wood and Patrick Seames. We are also grateful to our many colleagues at LBNL and University of California, Berkeley, who loaned us equipment that we used extensively during the conduct of the field experiments.

\section{REFERENCES}

Alzona, J., Cohen, B.L., Rudolph, H., Jow, H.N., and Frohlinger, J.O., 1979. Indoor-outdoor relationships for airborne particulate matter of outdoor origin. Atmospheric Environment, 13:55-60.

Byrne, M.A., Goddard, A.J.H., Lange, C. and Roed, J., 1995. Stable tracer aerosol deposition measurements in a test chamber. Journal of Aerosol Science, 26:645-653.

Dockery, D.W. and Spengler, J.D., 1981. Indoor-outdoor relationships of respirable sulfates and particles. Atmospheric Environment, 15:335-343.

Fogh, C.L., Byrne, M.A., Roed, J., and Goddard, A.J.H., 1997. Size specific indoor aerosol deposition measurements and derived I/O concentration ratios. Atmospheric Environment, 31:2193-2203.

Lee, Y.N. and Schwartz, S.E., 1981a. Reaction kinetics of nitrogen dioxide with liquid water at low partial pressure. J. Phys. Chem., 85:840-848.

Lee, Y.N. and Schwartz, S.E., 1981b. Evaluation of the rate of uptake of nitrogen dioxide by atmospheric and surface liquid water. J. Geophys. Res. 86, pp. 11791-11983.

Long, C.M., Suh, H.H., Catalano, P.J., and Koutrakis, P., 2001. Using time- and size-resolved particulate data to quantify indoor penetration and deposition behavior. Environmental Science and Technology, 35:2089-2099.

Mosley, R.B., Greenwell, D.J., Sparks, L.E., Guo, Z., Tucker, W.G., Fortmann, R., and Whitfield, C., 2001. Penetration of ambient fine particles into the indoor environment. Aerosol Science and Technology, 34:127-136.

Offermann, F.J., Sextro, R.G., Fisk, W.J.,Grimsrud, D.T., Nazaroff, W.W., Nero, A.V.,Revzan, K.L., and Yater, J., 1985. Control of respirable particles in indoor air with portable air cleaners. Atmospheric Environment, 19: 1761-1771.

Ozkaynak, H., Xue, J., Spengler, J., Wallace, L., Pellizzari, E. and Jenkins, P., 1996. Personal exposure to airborne particles and metals: results from the Particle Team study in Riverside, California. Journal of Exposure Analysis and Environmental Epidemiology, 6(1):57-78.

Stolzenburg, M.R. and Hering, S.V., 2000. Method for the automated measurement of fine particle nitrate in the atmosphere. Environmental Science and Technology, 34: 907-914.

Thatcher, T.L., and Layton, D.W., 1995. Deposition, resuspension, and penetration of particles within a residence. Atmospheric Environment, 29(13):1487-1497. 
Thatcher, T.L., Lai, A.C.K., Moreno-Jackson, R., Sextro, R.G., and Nazaroff, W.W., 2001. Effects of room furnishings and air speed on particle deposition rates indoors. LBNL-48414. Lawrence Berkeley National Laboratory, Berkeley, CA.

Vette, A.F., Rea, A.W., Lawless, P.A., Rodes, C.E., Evans, G., Highsmith, V.R., and Sheldon, L., 2001. Characterization of indoor-outdoor aerosol concentration relationships during the Fresno PM exposure studies. Aerosol Science and Technology, 34: 118-126.

Walker, I.S. and Wilson, D.J., 1998. Field validation of algebraic equations for stack and wind driven air infiltration calculations. HVAC\&R RESEARCH, 4(N2):119-139.

Wallace, L., 1996. Indoor particles: A review. Journal of the Air \& Waste Management Association, 46:98-126.

Xu, M.D., Nematollahi, M., Sextro, R.G., Gadgil, A.J., and Nazaroff, W.W., 1994. Deposition of tobacco smoke particles in a low ventilation room. Aerosol Science and Technology, 20:194206. 